\title{
Differences in Mental Health Diagnoses between Recent Chinese Immigrants and a Comparison Population in British Columbia
}

Différences dans les diagnostics en santé mentale entre les immigrants chinois récents et un échantillon comparatif de la population en Colombie-Britannique

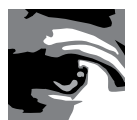

by ALICE W. CHEN, PHD

Adjunct Professor, Faculty of Health Sciences

Simon Fraser University

Vancouver, BC

ARMINÉE KAZANJIAN, DRSOC

Professor, School of Population and Public Health

University of British Columbia

Vancouver, BC

HUBERT WONG, PHD

Assistant Professor, School of Population and Public Health

University of British Columbia

Vancouver, BC 
Differences in Mental Health Diagnoses between Recent Chinese Immigrants and a Comparison Population in British Columbia

\author{
ROBERT J. REID, MD, PHD \\ Associate Investigator, Center for Health Studies \\ Group Health Cooperative \\ Seattle, WA
}

\begin{abstract}
Linked administrative data indicate that the distributions of mental health diagnoses are different for recent Chinese immigrants in British Columbia compared to a matched group reflecting the general population, as recorded in payments to general practitioners and psychiatrists between 1992 and 2001. Chinese immigrants were much less likely to have consultations for the mental disorders that were most common in the general population. Among those who saw a psychiatrist, psychotic conditions accounted for a larger proportion of visits for Chinese immigrants than those from the general population. The opposite was true for depressive conditions. The findings illuminate nuances in the disparity in mental health service utilization between Chinese immigrants and the general population.
\end{abstract}

\title{
Résumé
}

Lanalyse des données administratives portant sur les paiements versés aux omnipraticiens et aux psychiatres, entre 1992 et 2001, indique une différence dans la distribution des diagnostics en santé mentale entre les immigrants chinois récents et un échantillon représentatif de la population générale en Colombie-Britannique. Les immigrants chinois sont beaucoup moins enclins à demander une consultation pour les troubles mentaux les plus fréquents dans la population générale. De ceux qui ont consulté un psychiatre, une plus grande proportion de leurs visites était pour des états psychotiques comparé à la population générale. L'opposé est vrai pour des états dépressifs ou névrotiques. Ces résultats font voir des nuances dans les disparités entre les immigrants chinois et la population générale pour l'utilisation des services de santé mentale.

\footnotetext{
$\mathrm{S}$ ERVING THE MENTAL HEALTH NEEDS OF IMMIGRANTS AND MINORITIES IS a growing challenge in many immigrant-receiving nations that are becoming more ethnically diverse. The research literature suggests that immigrants, especially Asian immigrants, in several countries are less likely to use mental health services (Abe-Kim et al. 2007; Bebbington et al. 2000; Cheung and Snowden 1990; Harris et al. 2005; Kirmayer et al. 1996; Klimidis et al. 2000; Lai et al. 2003; Leong 1994;
} 
Matsuoka et al. 1997; Roberts and Crockford 1997; Snowden and Cheung 1990). In British Columbia, one-third of the new arrivals in 2006 came from Chinese territories (BC Stats 2007) and 16\% of the 2 million residents in the census metropolitan area of Vancouver reported Chinese as their first language (Stats Canada 2007). A previous study in British Columbia also reports that, relative to a comparison group of nonimmigrants and longer-term immigrants, recent Chinese immigrants have only $14 \%$ to $20 \%$ as many mental health visits to general practitioners and $10 \%$ to $11 \%$ as many psychiatric visits (Chen and Kazanjian 2005). The objective of this study was to investigate the diagnoses associated with the mental health visits and how the patterns of diagnoses may contribute to the disparity in utilization of mental health services.

\section{Methods}

Two administrative databases were paired by probabilistic linkage for a Canadian immigrant health research study: (a) the national immigration database from Citizenship and Immigration Canada of all immigrants who landed in British Columbia from 1985 to 2000 and (b) the province's health database, comprising information from health plan registration and physicians fee-for-service payments (DesMeules et al. 2004). Immigrants who came from China, Taiwan, Hong Kong or Macau and who registered in the provincial health plan at any time from 1992 to 2001 were selected for this study. Each immigrant was matched by sex, year of birth and local health area to a comparison subject who was randomly selected from the BC health plan registration file, excluding those in the immigration database. The final study group consisted of 148,973 pairs of subjects. Observation for each pair began after the immigrant's landing.

All mental health visits to general practitioners and all visits to psychiatrists for the study group during the study period were extracted for analysis. A "visit" was defined to include all inpatient and outpatient services paid to a physician for an individual in one day. Mental health visits to general practitioners were identified by the diagnostic and service information in the records. The diagnostic categories of mental health visits to general practitioners and psychiatrists were tabulated to provide an overview of the reasons for mental health visits and to show differences between immigrants and comparison group members in the patterns of mental health diagnoses recorded. The frequency of each diagnostic category, the percentage of the total number of visits, the number and percentage of individuals involved in each category and the number of visits per diagnosed individual for that diagnostic category were calculated. The precision of the percentage of each diagnostic category is reported using a $95 \%$ confidence interval. Differences between immigrant and comparison group can be considered to be statistically significant at the $5 \%$ level if the confidence intervals do not overlap, or overlap by no more that 25\% (Van Belle 2002, 
Differences in Mental Health Diagnoses between Recent Chinese Immigrants and a Comparison Population in British Columbia

p.39-40). Statistical analyses were performed using SAS 9.1. To account for multiple visits by each individual, the confidence intervals were calculated using PROC SURVEYFREQ and treating each study ID as a cluster.

\section{Results}

The study population consisted of $51 \%$ women and $49 \%$ men, with mean age being 34 . The median landing year for immigrants was 1995, and the average length of observation for both immigrants and comparison subjects was over five years. Over $95 \%$ of the Chinese immigrants resided in the Metro Vancouver region. Tables 1 and 2 summarize the top 10 diagnostic categories of all the eligible mental health visits made to general practitioners and psychiatrists between 1992 and 2001 by Chinese immigrants and by the comparison subjects; the number and percentage of visits; the number and percentage of individuals involved in each category; and the mean number of visits per diagnosed individual for each category. The results support previous findings that fewer immigrants consulted physicians for mental health reasons, and that they had far fewer visits than the comparison group. The results also indicate that the frequency of diagnostic categories differed between the two groups. For Chinese immigrants, almost half the mental health visits with general practitioners were for anxiety/depression, a category unique to British Columbia's health plan and which covers a variety of subclinical depressive and anxiety symptoms. A quarter of the comparison group's mental health visits to general practitioners were for drug dependence, a diagnosis that was rare among the immigrants; anxiety/depression and depressive disorder not elsewhere classified (NEC) were the next most frequent categories.

The main categories associated with psychiatric visits for Chinese immigrants were affective psychoses and neurotic disorders, followed by schizophrenic psychoses and depressive disorder NEC. For comparison subjects, the main reasons for psychiatric visits were depressive disorder NEC and neurotic disorders, with affective psychoses being the third most likely reason. Relative to comparison subjects, immigrants who received psychiatric care were more likely to do so for serious mental disorders such as schizophrenic and affective psychoses.

\section{Discussion}

While recent Chinese immigrants are much less likely to consult physicians for mental health reasons in general, this study suggests that they also differ in their distribution of diagnostic categories such that the disparity in rate of visits is not uniform across all conditions. For instance, Chinese immigrants were even less likely to consult a general practitioner for drug dependence and depressive disorder NEC - two conditions that account for a sizeable portion of the utilization among comparison subjects. 
Alice W. Chen et al.

TABLE 1. Top 10 diagnostic categories of mental health visits to general practitioners by Chinese immigrants and comparison subjects in |992-200 I

\begin{tabular}{|c|c|c|c|c|c|c|}
\hline \multicolumn{7}{|c|}{ Immigrants } \\
\hline Diagnostic category & $\begin{array}{c}\text { \# of } \\
\text { subjects' }\end{array}$ & $\begin{array}{c}\% \text { of } \\
\text { subjects }{ }^{2}\end{array}$ & $\begin{array}{l}\# \text { of } \\
\text { visits }\end{array}$ & $\begin{array}{l}\text { Rate of } \\
\text { visits }^{3}\end{array}$ & $\begin{array}{l}\% \text { of } \\
\text { visits }\end{array}$ & $95 \% \mathrm{Cl}$ \\
\hline Anxiety/Depression ${ }^{4}$ & 17,452 & $11.7 \%$ & 37,636 & 2.2 & $46.0 \%$ & $(45.1 \%, 46.9 \%)$ \\
\hline Neurotic Disorders & 8,189 & $5.5 \%$ & 16,111 & 2.0 & $19.7 \%$ & $(19.1 \%, 20.3 \%)$ \\
\hline Depressive Disorder NEC & 3,648 & $2.4 \%$ & 8,655 & 2.4 & $10.6 \%$ & $(10.1 \%, 11.1 \%)$ \\
\hline Acute Reaction to Stress & 4,073 & $2.7 \%$ & 7,300 & 1.8 & $8.9 \%$ & $(8.5 \%, 9.3 \%)$ \\
\hline $\begin{array}{l}\text { Special Symptoms or } \\
\text { Syndromes NEC }\end{array}$ & 2,439 & $1.6 \%$ & 3,747 & 1.5 & $4.6 \%$ & $(4.3 \%, 4.8 \%)$ \\
\hline Adjustment Reaction & I, 147 & $0.8 \%$ & । ,747 & 1.5 & $2.1 \%$ & $(2.0 \%, 2.3 \%)$ \\
\hline Drug Dependence & 131 & $0.1 \%$ & 1,425 & 10.9 & $1.7 \%$ & $(0.8 \%, 2.7 \%)$ \\
\hline Schizophrenic Psychoses & 285 & $0.2 \%$ & 1,217 & 4.3 & $1.5 \%$ & $(1.2 \%, 1.8 \%)$ \\
\hline $\begin{array}{l}\text { Sexual Deviations \& } \\
\text { Disorders }\end{array}$ & 380 & $0.3 \%$ & 564 & 1.5 & $0.7 \%$ & $(0.6 \%, 0.8 \%)$ \\
\hline Personality Disorders & 312 & $0.2 \%$ & 528 & 1.7 & $0.6 \%$ & $(0.5 \%, 0.7 \%)$ \\
\hline TOTAL $^{5}$ & 30,395 & $20.4 \%$ & 81,774 & 2.7 & $100 \%$ & \\
\hline \multicolumn{7}{|c|}{ Comparison } \\
\hline Diagnostic category & $\begin{array}{c}\text { \# of } \\
\text { subjects' }\end{array}$ & $\begin{array}{c}\% \text { of } \\
\text { subjects }{ }^{2}\end{array}$ & $\begin{array}{l}\text { \# of } \\
\text { visits }\end{array}$ & $\begin{array}{l}\text { Rate of } \\
\text { visits }^{3}\end{array}$ & $\begin{array}{l}\% \text { of } \\
\text { visits }\end{array}$ & $95 \% \mathrm{Cl}$ \\
\hline Drug Dependence & 2,680 & $1.8 \%$ & 102,659 & 38.3 & $25.0 \%$ & $(22.8 \%, 27.2 \%)$ \\
\hline Anxiety/Depression ${ }^{4}$ & 28,165 & $18.9 \%$ & 90,398 & 3.2 & $22.0 \%$ & $(21.3 \%, 22.8 \%)$ \\
\hline Depressive Disorder NEC & 18,992 & $12.7 \%$ & 83,219 & 4.4 & $20.3 \%$ & $(19.5 \%, 21.0 \%)$ \\
\hline Neurotic Disorders & 17,350 & $11.6 \%$ & 47,534 & 2.7 & $11.6 \%$ & $(11.1 \%, 12.0 \%)$ \\
\hline Acute Reaction to Stress & 11,647 & $7.8 \%$ & $26,97 \mid$ & 2.3 & $6.6 \%$ & $(6.3 \%, 6.9 \%)$ \\
\hline Adjustment Reaction & 5,396 & $3.6 \%$ & 13,032 & 2.4 & $3.2 \%$ & $(2.9 \%, 3.5 \%)$ \\
\hline $\begin{array}{l}\text { Special Symptoms or } \\
\text { Syndromes NEC }\end{array}$ & 3,575 & $2.4 \%$ & 6,913 & 1.9 & $1.7 \%$ & $(1.6 \%, 1.8 \%)$ \\
\hline $\begin{array}{l}\text { Alcohol Dependence } \\
\text { Syndrome }\end{array}$ & 1,918 & $1.3 \%$ & 6,893 & 3.6 & $1.7 \%$ & $(1.5 \%, 1.8 \%)$ \\
\hline Schizophrenic Psychoses & 910 & $0.6 \%$ & 6,241 & 6.9 & $1.5 \%$ & $(1.3 \%, 1.8 \%)$ \\
\hline $\begin{array}{l}\text { Non-dependent Abuse of } \\
\text { Drugs }\end{array}$ & 600 & $0.4 \%$ & 4,674 & 7.8 & $1.1 \%$ & $(0.6 \%, 1.7 \%)$ \\
\hline TOTAL $^{5}$ & 58,508 & $39.3 \%$ & 410,295 & 7.0 & $100 \%$ & \\
\hline
\end{tabular}

I Individual subjects may be treated for more than one diagnosis

2 Percentage of the 148,973 subjects who received the diagnostic category

${ }^{3}$ Number of visits per person diagnosed

${ }^{4} \mathrm{BC}$ diagnostic category; all the others are based on ICD-9

${ }^{5}$ The total number and percentage include all diagnostic categories 
Differences in Mental Health Diagnoses between Recent Chinese Immigrants and a Comparison Population in British Columbia

TABLE 2. Top 10 diagnostic categories of mental health visits to psychiatrists by Chinese immigrants and comparison subjects in 1992-200 I

\begin{tabular}{|c|c|c|c|c|c|c|}
\hline \multicolumn{7}{|c|}{ Immigrants } \\
\hline Diagnostic category & $\begin{array}{c}\text { \# of } \\
\text { subjects' }\end{array}$ & $\begin{array}{c}\% \text { of } \\
\text { subjects }^{2}\end{array}$ & $\begin{array}{l}\text { \# of } \\
\text { visits }\end{array}$ & $\begin{array}{l}\text { Rate of } \\
\text { visits }^{3}\end{array}$ & $\begin{array}{l}\% \text { of } \\
\text { visits }\end{array}$ & $95 \% \mathrm{Cl}$ \\
\hline Affective Psychoses & 690 & $0.5 \%$ & 6,336 & 9.2 & $24.7 \%$ & $(22.0 \%, 27.4 \%)$ \\
\hline Neurotic Disorders & 704 & $0.5 \%$ & 5,222 & 7.4 & $20.3 \%$ & $(17.2 \%, 23.5 \%)$ \\
\hline Schizophrenic Psychoses & 217 & $0.1 \%$ & 3,719 & 17.1 & $14.5 \%$ & $(11.7 \%, 17.2 \%)$ \\
\hline Depressive Disorder NEC & 404 & $0.3 \%$ & 3,679 & 9.1 & $14.3 \%$ & $(11.7 \%, 17.0 \%)$ \\
\hline Adjustment Reaction & 425 & $0.3 \%$ & $|, 6| 1$ & 3.8 & $6.3 \%$ & $(5.1 \%, 7.4 \%)$ \\
\hline $\begin{array}{l}\text { Other Non-organic } \\
\text { Psychoses }\end{array}$ & 114 & $0.1 \%$ & 1,109 & 9.7 & $4.3 \%$ & $(2.7 \%, 5.9 \%)$ \\
\hline $\begin{array}{l}\text { Hyperkinetic Syndrome of } \\
\text { Childhood }\end{array}$ & 72 & $<0.05 \%$ & 741 & 10.3 & $2.9 \%$ & $(1.9 \%, 3.8 \%)$ \\
\hline $\begin{array}{l}\text { Disturbance of Emotions- } \\
\text { Childhood and Adolescence }\end{array}$ & 97 & $0.1 \%$ & 592 & 6.1 & $2.3 \%$ & $(1.5 \%, 3.1 \%)$ \\
\hline $\begin{array}{l}\text { Transient Organic Psychotic } \\
\text { Conditions }\end{array}$ & 70 & $<0.05 \%$ & 490 & 7.0 & $1.9 \%$ & $(1.1 \%, 2.7 \%)$ \\
\hline Other Diagnoses ${ }^{4}$ & 72 & $<0.05 \%$ & 404 & 5.6 & $1.6 \%$ & $(0.7 \%, 2.4 \%)$ \\
\hline TOTAL $^{5}$ & 2,266 & $1.5 \%$ & 25,672 & 11.3 & $100 \%$ & \\
\hline \multicolumn{7}{|c|}{ Comparison } \\
\hline Diagnostic category & $\begin{array}{c}\text { \# of } \\
\text { subjects' }\end{array}$ & $\begin{array}{c}\% \text { of } \\
\text { subjects }^{2}\end{array}$ & $\begin{array}{l}\text { \# of } \\
\text { visits }\end{array}$ & $\begin{array}{l}\text { Rate of } \\
\text { visits }\end{array}$ & $\begin{array}{l}\% \text { of } \\
\text { visits }\end{array}$ & $95 \% \mathrm{Cl}$ \\
\hline Depressive Disorder NEC & 3,756 & $2.5 \%$ & 45,489 & 12.1 & $23.7 \%$ & $(22.1 \%, 25.2 \%)$ \\
\hline Neurotic Disorders & 3,430 & $2.3 \%$ & 44,447 & 13.0 & $23.1 \%$ & $(21.5 \%, 24.8 \%)$ \\
\hline Affective Psychoses & 2,262 & $1.5 \%$ & 26,657 & 11.8 & $13.9 \%$ & $(\mid 2.7 \%, 15.0 \%)$ \\
\hline Adjustment Reaction & 2,199 & $1.5 \%$ & 17,922 & 8.2 & $9.3 \%$ & $(8.4 \%, 10.3 \%)$ \\
\hline Schizophrenic Psychoses & 837 & $0.6 \%$ & $|3,76|$ & 16.4 & $7.2 \%$ & $(6.3 \%, 8.0 \%)$ \\
\hline Anxiety/Depression & 682 & $0.5 \%$ & 8,920 & 13.1 & $4.6 \%$ & $(3.7 \%, 5.6 \%)$ \\
\hline Personality Disorders & 589 & $0.4 \%$ & 5,700 & 9.7 & $3.0 \%$ & $(2.4 \%, 3.6 \%)$ \\
\hline $\begin{array}{l}\text { Disturbance of Emotions- } \\
\text { Childhood and Adolescence }\end{array}$ & 487 & $0.3 \%$ & 4,152 & 8.5 & $2.2 \%$ & $(1.8 \%, 2.6 \%)$ \\
\hline $\begin{array}{l}\text { Special Symptoms or } \\
\text { Syndromes NEC }\end{array}$ & 409 & $0.3 \%$ & 3,945 & 9.6 & $2.1 \%$ & $(1.4 \%, 2.7 \%)$ \\
\hline Other Diagnoses ${ }^{4}$ & 664 & $0.4 \%$ & 3,942 & 5.9 & $2.0 \%$ & $(1.6 \%, 2.5 \%)$ \\
\hline TOTAL $^{5}$ & 11,388 & $7.6 \%$ & 192,304 & 16.9 & $100 \%$ & \\
\hline
\end{tabular}

I Individual subjects may be treated for more than one diagnosis

2 Percentage of the 148,973 subjects who received the diagnostic category

3 Number of visits per person diagnosed

${ }^{4}$ Consists of non-psychiatric diagnoses such as developmental delays, psychic factors associated with other diseases, mental retardation, other conditions of brain and the nervous system, general symptoms, other family circumstances

5 The total number and percentage include all diagnostic categories 
As a result, whereas Chinese immigrants had $20 \%$ as many mental health visits to general practitioners as the comparison group overall, the relative rates for drug dependence and depressive disorder NEC were $1 \%$ and $10 \%$, respectively. In psychiatry, the immigrants were relatively more likely to visit for psychotic conditions and less likely to visit for depressive conditions. While the immigrants had $13 \%$ as many psychiatric visits overall as the comparison group, the percentages for affective psychoses and schizophrenic psychoses were higher at $24 \%$ and $27 \%$, respectively, and the percentages for depressive disorder NEC and adjustment reaction were lower at $8 \%$ and $9 \%$, respectively. That is, the disparities between immigrants and comparison subjects are relatively smaller for the serious but rare disorders of affective psychoses and schizophrenic psychoses but relatively larger for the less serious depressive conditions. Because the less serious depressive conditions comprise a large proportion of visits to psychiatrists, the disparity in psychiatric service utilization between immigrants and comparison subjects is more complex than the overall numbers would suggest.

Canada's immigration policy favours immigrants with greater educational attainment, financial assets and employability - all social determinants of health. Therefore, it is plausible to infer that immigrants would have better mental health status and lower overall rates of mental health service utilization. There is evidence from several studies of the Canadian Community Health Survey (CCHS) that the prevalence of mental disorders is lower among immigrants in general and Chinese immigrants in particular. These studies report that Asian immigrants in Canada and Chinese immigrants in British Columbia have lower risks for major depressive episode (Ali 2002; Chen 2006). Recent immigrants in Canada are also less likely to rate their mental health as poor (Lou and Beaujot 2005). However, the CCHS study of Chinese immigrants in British Columbia found that, even after controlling for depressive symptoms, Chinese immigrants were still much less likely to seek mental health consultation (Chen 2006). There is currently no evidence that difference in prevalence of mental disorders between the immigrant and the native-born population varies by type of disorder. Considering the selective nature of Canada's immigration policy, one would expect that the prevalence of chronic and serious disorders would be even lower among immigrants, contrary to the pattern of relative distribution of visits observed in our study. Hence, the differential distribution in the treated mental conditions in this study suggests that use of healthcare services is not uniform for all mental health conditions.

Several caveats should be kept in mind in interpreting the findings of this study. One concerns the composition of the comparison group. The group consisted of individuals who were matched by sex and age to the immigrant population; therefore, they represent a population that is somewhat younger than the general non-immigrant population in the province. The group is also likely to include a small percentage of longer-term immigrants who arrived before 1985 .

A second caveat concerns the limitations inherent in the data sources. The physi- 
Differences in Mental Health Diagnoses between Recent Chinese Immigrants and a Comparison Population in British Columbia

cian payments file contains only information on fee-for-service payments and excludes services delivered under alternative billing schemes. An estimate of the coverage of the fee-for-service payments for the fiscal year 1996/97 is $96.0 \%$ for general practitioners and $67.5 \%$ for psychiatrists (Kazanjian et al. 2000). Thus, the payments file covers most of the general practitioner services and a smaller percentage of psychiatric services. Most of the remaining psychiatric service is delivered through the mental health service system. The rate ratio between Chinese immigrants and the comparison group of utilization of fee-for-service psychiatrists (0.14) and of the mental health system (0.13) is similar (Chen 2006), although the distribution of diagnostic categories in the mental health system is not known. Since the mental health system tends to treat serious and chronic disorders, the omission of those data may skew the distribution of diagnostic categories reported in this study towards the less serious disorders.

Another issue associated with the data sources is that the validity of the diagnostic codes in the health database is not verified and only one code is required for each payment claim. Hence, co-morbid mental health diagnoses may not have been identified. There may be cultural bias in coding such that certain diagnoses are systematically over- or underreported in the Chinese immigrant or the comparison group members. However, to the extent that the diagnostic code reflects intervention delivered, the discrepancies observed in the diagnostic codes still raise the concern that some diagnoses may be undertreated among members of the group. A related issue with regard to the health database is that it contains only information on individuals who have come into contact with the medical system. Hence, this study sheds light only on differences in utilization of medical care between the populations studied. Questions about access to care are contingent upon knowledge of both the prevalence rates of different types of mental disorders and the intervention received after seeking care.

The Chinese immigrant population is not a homogeneous group. A previous study has shown that various individual characteristics - such as years since landing, general use of primary care, age, place of origin, educational level, marital status, English skills - influence the rate of mental health consultation (Chen et al. 2008). It is reasonable to assume that the distribution of diagnostic categories relative to the comparison group also varies among the subpopulations. Future studies will have to explore the complexities of the disparities observed in this study.

This study demonstrates that secondary analysis of linked administrative databases can be a useful tool in understanding utilization by immigrant and ethnic minority groups. The comprehensive information in the databases quantifies the magnitude of disparities and illuminates some of the nuances. Lower rates of consultation for mental disorders that are most common in the general population, such as depressive disorder NEC and drug dependence, account for a large portion of the disparity in utilization frequently reported for the immigrant population. Even though recent immigrants may face various barriers in accessing healthcare for all types of mental 
disorders, a larger gap exists in the utilization of specialist services for the most common, though less recognizable, mental disorders.

The findings of this study can inform efforts to improve access to mental health services for newcomers and reduce the gap in utilization. While public attention usually focuses on severe forms of mental disorder, the more pervasive though milder conditions underlie much of the discrepancy in utilization. Chinese immigrants may be less disposed culturally to recognize subtle symptoms such as depression (Leong and Lau 2001). Even when they recognize mental health problems, Asians may be reluctant to discuss them because of shame and stigma (Leong and Lau 2001; Li et al. 1999). Hence, only when the symptoms become severe do these patients come to medical attention. For immigrants to use the same amount of professional and selfhelp mental health resources as the Canadian-born, they would have to perceive their mental health as much poorer than the Canadian-born (Lou and Beaujot 2005). However, even when these mild mental and emotional disturbances are not acknowledged as such, they may manifest as somatic complaints and may impair social and vocational functioning. The prevalence of these unrecognized or untreated disorders translates into high social, economic and healthcare costs, as well as large discrepancies in indicators of service utilization (Eaton et al. 2008; Stephens and Joubert 2001). Interventions directed at the most severe and chronic forms of mental disorder (i.e., a strategic focus on relatively few, severely affected individuals) may have great benefits to personal lives and outcomes, but breaking down the barriers for the less serious and less recognizable conditions (i.e., treating a broader segment of moderately affected individuals) will have greater impact on health status at a population level (WHO 2008). Targeting these common conditions will also enable the health system to achieve greater strides towards the goal of equity in utilization.

True equity in access to services is a more elusive goal, in terms of demonstrating its achievement. Several components are involved in the assessment of access: the need for services, the types of services needed and the outcomes of service use. Cutting through each component is the cultural dimension. Whether existing diagnostic codes and criteria are appropriate for cultural minority groups is still an outstanding debate. The effect of mental disorders on an individual's life may also vary culturally, leading to different needs for services and different types of services that may be of benefit. The acceptability of a service and its form of delivery will also have to be considered. The yardstick to measure equity in access must ultimately address health status outcomes, of which there can also be different interpretations. Future research will have to focus on defining and measuring the need for and outcomes of mental health services in the culturally diverse population that characterizes Canada. Cultural diversity, as much as increasing longevity and changing lifestyle, should be one of the factors that drive health policy decisions. 
Differences in Mental Health Diagnoses between Recent Chinese Immigrants and a Comparison Population in British Columbia

ACKNOWLEDGEMENTS

Dr. Chen was supported by a doctoral training award from the Canadian Institutes of Health Research; a Western Regional Training Centre studentship funded by Canadian Health Services Research Foundation, Alberta Heritage Foundation for Medical Research and Canadian Institutes of Health Research; and a Research in Addictions and Mental Health Policy and Services award, funded by Canadian Institutes of Health Research.

Correspondence may be directed to: Alice Chen, PhD, University Research Associate, Children's Health Policy Centre, Faculty of Health Sciences, Simon Fraser University, \#2431-515 West Hastings Street, Vancouver, BC V6B 5K3; tel.: 778-782-7669; e-mail: alicechen@sfu.ca.

\section{REFERENCES}

Abe-Kim, J., D.T. Takeuchi, S. Hong, N. Zane, S. Sue, M.S. Spencer, H. Appel, E. Nicdao and M. Alegria. 2007. "Use of Mental Health-Related Services among Immigrant and US-born Asian Americans: Results from the National Latino and Asian American Study" American Journal of Public Health 97(1): 91-98.

Ali, J. 2002. Mental Health of Canada's Immigrants. Health Reports Catalogue 82-003 (Rep. No. 13 [Supplement]). Ottawa: Statistics Canada.

BC Stats. 2007. "BC Immigration by Top 10 Source by Class, January to December 2006."

Retrieved May 15, 2009. <http://www.bcstats.gov.bc.ca/data/pop/mig/imm06t4a.pdf>.

Bebbington, P.E., H. Meltzer, T.S. Brugha, M. Farrell, R. Jenkins, C. Ceresa and G. Lewis. 2000. "Unequal Access and Unmet Need: Neurotic Disorders and the Use of Primary Care Services." Psychological Medicine 30: 1359-67.

Chen, A.W. 2006. Mental Health Service Utilization by Chinese Immigrants and Canadian-Born Chinese in British Columbia. PhD dissertation. Vancouver: University of British Columbia.

Chen, A.W. and A. Kazanjian. 2005. "Rate of Mental Health Service Utilization by Chinese Immigrants in British Columbia." Canadian Journal of Public Health 96(1): 49-51.

Chen, A.W., A. Kazanjian and H. Wong. 2008. "Determinants of Mental Health Consultations among Recent Chinese Immigrants in British Columbia, Canada: Implications for Mental Health Risk and Access to Services." Journal of Immigrant and Minority Health 10(6): 529-40.

Cheung, F.K. and L.R. Snowden. 1990. “Community Mental Health and Ethnic Minority Populations." Community Mental Health Journal 26(3): 277-91.

DesMeules, M., J. Gold, A. Kazanjian, D. Manuel, J. Payne, B. Vissandee, S. McDermott and Y. Mao. 2004. "New Approaches to Immigrant Health Assessment." Canadian Journal of Public Health 95(3): I22-I26.

Eaton, W.W., S.S. Martin, G. Nestadt, O.J. Bienvenu, D. Clarke and P. Alexandre. 2008.“The Burden of Mental Disorders." Epidemiologic Reviews 30(1): 1-14.

Harris, K.M., M.J. Edlund and S. Larson. 2005."Racial and Ethnic Differences in the Mental Health Problems and Use of Mental Health Care." Medical Care 43(8): 775-84.

Kazanjian, A., R.J. Reid, N. Pagliccia, L. Apland and L. Wood. 2000. Issues in Physician Resources Planning in BC: Key Determinants of Supply and Distribution, 1991-96 (Rep. No. HHRU 00:02). 
Vancouver: Centre for Health Services and Policy Research, University of British Columbia. Kirmayer, L.J., G. Galbaud du Fort, A. Young, M. Weinfeld and J.-C. Lasry. 1996. Pathways and Barriers to Mental Health Care in an Urban Multicultural Milieu: An Epidemiological and Ethnographic Study. Culture E Mental Health Research Unit Report (Rep. No. 6 [Part 1]). Montreal: Culture \& Mental Health Research Unit, Sir Mortimer B. Davis - Jewish General Hospital.

Klimidis, S., D.P. McKenzie, J. Lewis and I.H. Minas. 2000. "Continuity of Contact with Psychiatric Services: Immigrant and Australian-Born Patients." Social Psychiatry and Psychiatric Epidemiology 35: 554-63.

Lai, D.W.L., K.T. Tsang, N.L. Chappell, D.C.Y. Lai and S.B.Y. Chau. 2003. Health and Well-Being of Older Chinese in Canada. Calgary: Faculty of Social Work, University of Calgary.

Leong, F.T.L. 1994. “Asian Americans’ Differential Patterns of Utilization of Inpatient and Outpatient Public Mental Health Services in Hawaii." Journal of Community Psychology 22: 82-96. Leong, F.T.L. and A.S.L. Lau. 2001. "Barriers to Providing Effective Mental Health Services to Asian Americans." Mental Health Services Research 3(4): 201-14.

Li, P-L., S. Logan, L. Yee and S. Ng. 1999. "Barriers to Meeting the Mental Health Needs of the Chinese Community." Journal of Public Health Medicine 21(1): 74-80.

Lou, Y. and R. Beaujot. 2005. What Happens to the "Healthy Immigrant Effect": The Mental Health of Immigrants to Canada (Discussion Paper No. 05-15). London, ON: Population Studies Centre, University of Western Ontario.

Matsuoka, J.K., C. Breaux and D.H. Ryujin. 1997."National Utilization of Mental Health Services by Asian Americans/Pacific Islanders." Journal of Community Psychology 25(2): 141-45.

Roberts, N. and D. Crockford. 1997. "Psychiatric Admissions of Asian Canadians to an Adolescent Inpatient Unit." Canadian Journal of Psychiatry 42: 847-51.

Snowden, L.R. and F.K. Cheung. 1990. “Use of Inpatient Mental Health Services by Members of Ethnic Minority Groups." American Psychologist 45(3): 347-55.

Stephens, T. and N. Joubert. 2001."The Economic Burden of Mental Health Problems in Canada." Chronic Diseases in Canada 22(1), 18-23.

Statistics Canada. 2007. "Profile of Language, Immigration, Citizenship, Mobility and Migration for Census Metropolitan Areas and Census Agglomerations, 2006 Census." Cat. No. 94-577. XCB2006004. Retrieved May 15, 2009. <http://www12.statcan.ca/english/census06/data/profiles/release/RetrieveProductTable.cfm?'Temporal=2006\&APATH=3\&PID=89773\&THEME $=$ $70 \& \mathrm{PTYPE}=89103 \& \mathrm{VID}=0 \& \mathrm{GK}=\mathrm{NA} \& \mathrm{GC}=99 \& \mathrm{FL}=0 \& \mathrm{RL}=0 \& \mathrm{FREE}=0 \& \mathrm{METH}=0 \& \mathrm{~S}=$ $1 \& \mathrm{GID}=777244>$.

Van Belle, G. 2002. Statistical Rules of Thumb. New York: John Wiley \& Sons.

World Health Organization. 2008. The Global Burden of Disease: 2004 Update. Available at http://www.who.int/healthinfo/global_burden_disease/2004_report_update/en/index.html 